\title{
Design of Multijunction Photovoltaic Cells Optimized for Varied Atmospheric Conditions
}

\author{
C. Zhang, ${ }^{1}$ J. Gwamuri, ${ }^{1}$ R. Andrews, ${ }^{2}$ and J. M. Pearce ${ }^{1,3}$ \\ ${ }^{1}$ Department of Materials Science \& Engineering, Michigan Technological University, Houghton, MI 49931-1295, USA \\ ${ }^{2}$ Department of Mechanical and Materials Engineering, Queen's University, Kingston, ON, Canada K7L 3N6 \\ ${ }^{3}$ Department of Electrical \& Computer Engineering, Michigan Technological University, Houghton, MI 49931-1295, USA
}

Correspondence should be addressed to J. M. Pearce; pearce@mtu.edu

Received 2 June 2014; Accepted 15 October 2014; Published 6 November 2014

Academic Editor: Wayne A. Anderson

Copyright (c) 2014 C. Zhang et al. This is an open access article distributed under the Creative Commons Attribution License, which permits unrestricted use, distribution, and reproduction in any medium, provided the original work is properly cited.

\begin{abstract}
Band gap engineering provides an opportunity to not only provide higher overall conversion efficiencies of the reference AM1.5 spectra but also customize PV device design for specific geographic locations and microenvironments based on atmospheric conditions characteristic to that particular location. Indium gallium nitride and other PV materials offer the opportunity for limited bandgap engineering to match spectra. The effects of atmospheric conditions such as aerosols, cloud cover, water vapor, and air mass have been shown to cause variations in spectral radiance that alters PV system performance due to both overrating and underrating. Designing PV devices optimized for spectral radiance of a particular region can result in improved PV system performance. This paper presents a new method for designing geographically optimized PV cells with using a numerical model for bandgap optimization. The geographic microclimate spectrally resolved solar flux for twelve representative atmospheric conditions for the incident radiation angle (zenith angle) of $48.1^{\circ}$ and fixed array angle of $40^{\circ}$ is used to iteratively optimize the band gap for tandem, triple, and quad-layer of InGaN-based multijunction cells. The results of this method are illustrated for the case study of solar farms in the New York region and discussed.
\end{abstract}

\section{Introduction}

The potential of selecting different solar photovoltaic (PV) materials to enable bandgap engineering to optimize the absorption of the complete solar spectrum is moving closer to reality. For example, indium gallium nitride $\left(\operatorname{In}_{x} \mathrm{Ga}_{1-x} \mathrm{~N}\right)$ alloys are promising thin-film PV materials for multijunction devices due to a tunable band gap from $0.7 \mathrm{eV}$ to 3.4 , which covers nearly the entire solar spectrum $[1,2]$. This promise has led to a recent explosion in scientific interest in the material as primary material for multijunction cells and significant PV device efficiency improvements have already been reported [1-18]. Although there are still challenges such as phase segregation, indium fluctuation, and lack of matched substrates in $\operatorname{In}_{x} \mathrm{Ga}_{1-x} \mathrm{~N}$ PV, there are no fundamental limitations to the material forming high-efficiency PV devices $[1-4,16,18]$. Theoretical work on $\operatorname{In}_{x} \mathrm{Ga}_{1-x} \mathrm{~N}$ has shown potential efficiencies of $42 \%$ for a double junction, $49 \%$ for a triple junction, and 53\% for a quad-layer PV device under
1 sun illumination with an AM1.5 spectrum [19]. However, in real-world applications, the energy conversion of solar cells depends on both the quantity and the spectral characteristics [20-22] of solar radiation that the cells receive and to what extent the junction layer band gaps match this solar radiation.

The spectrum illuminating a PV device can differ substantially from the reference spectrum as it varies with weather, temporally, geographically, and from the contributions from the microenvironments in which the PV are deployed. Thus $\mathrm{In}_{x} \mathrm{Ga}_{1-x} \mathrm{~N}$ multijunction PV technology and other similar materials systems offer not only the opportunity for higher overall conversion efficiencies of the reference AM1.5 spectra but also the novel opportunity to optimize PV cells geographically and for specific microenvironments based on the local air conditions. In this paper, a model is provided to simulate optimum band gaps using spectral data for different air conditions. This geographic microclimate spectrally resolved solar flux is used to iteratively optimize the band gap for tandem, triple, and quad-layer multijunction 
cells. The microenvironment contribution from various air conditions is evaluated and conclusions are about the implications of spectral consideration in PV system design involving multijunction solar cells.

\section{Methods}

Spectral data characteristics of particular atmospheric conditions were input into the Matlab-based band gap optimization code [23] and compared to the baseline band gaps obtained by inputting the AM 1.5 spectrum into the code. The entire spectral range from 0.28 to 2.5 microns for different atmospheric conditions, such as moderate to heavy cloud cover, moderate to heavy aerosol presence in the atmosphere, and heavily polluted air conditions, was integrated to produce a new reference spectrum for each condition. The generated characteristic reference spectrum was then input into the model for band gap engineering. Different atmospheric conditions and their effect on spectral radiance can be considered and band gap optimization repeated for each particular case of interest in future. The band gap optimization model makes use of computer modeled radiation energy loss monitoring program, which tries to minimize incident radiant energy loss by iteratively adjusting the available band gaps to absorb the most available energy. The model is a function of (1) the nature of the incident spectral radiant energy and (2) the number of available band gaps. The nature of the radiation incident on the PV is characteristic of a particular area associated with specific air conditions. Using this information, it is possible to design the most effective multijunction PV devices by changing the number of band gaps until optimization is achieved.

2.1. Spectral Modeling. The representative spectrum of incident light is reproduced using two simulations packages: SMARTS [24] and SBDART [25]. SMARTS was utilized for all clear sky spectrum generation, and SBDART was utilized to simulate the effects of cloud cover on these spectra. All atmospheric parameters in both programs were set to the SMARTS default values, unless explicitly stated otherwise. The sample spectra generated from atmospheric air conditions are shown in Figure 1 and detailed in Table 1. Figure 1 is broken into Figures 1(a) and 1(b) to enable more clear viewing of the spectra for the atmospheric conditions described in Table 1. The AM1.5 global spectrum was the baseline case scenario and is shown in Figures 1(a) and 1(b) to enable comparison of all of the spectra.

The PV system being analyzed is assumed to be at a latitude of $40^{\circ} \mathrm{N}$ in the New York region and at a fixed array angle of $40^{\circ}$.

2.2. Band Gap Engineering of Multijunction Cells. Band gap engineering aims at finding the band gap combinations that result in the minimum loss of energy of the incident light. All photons incident onto the solar cell may result in the generation of electron-hole pairs provided they have sufficient energy (i.e., greater than or equal to the band gap). In the case of the incoming photon energy being less than
TABLE 1: SMARTS and SBDART generated spectra.

\begin{tabular}{|c|c|}
\hline Name & Description \\
\hline \multicolumn{2}{|c|}{ SMARTS generated spectra } \\
\hline Base-case & AM1.5, SMARTS defaults \\
\hline Moderate aerosols & $\begin{array}{l}\text { AM1.5, SMARTS defaults with } \\
\text { Angstrom's coefficient of } 0.2\end{array}$ \\
\hline Heavy aerosols & $\begin{array}{l}\text { AM1.5, SMARTS defaults with } \\
\text { Angstrom's coefficient of } 0.4\end{array}$ \\
\hline Mid latitude winter & AM1.5, SMARTS Preset \\
\hline Mid latitude summer & AM1.5, SMARTS Preset \\
\hline Subarctic winter & AM1.5, SMARTS Preset \\
\hline Subarctic summer & AM1.5, SMARTS Preset \\
\hline Tropics & AM1.5, SMARTS Preset \\
\hline US62 & AM1.5, US 1962 standard atmosphere \\
\hline \multicolumn{2}{|c|}{ SBDART generated spectra } \\
\hline Moderate clouds & $\begin{array}{l}\text { AM1.5, SMARTS defaults translated to } \\
\text { SBDART, with cloud optical depth of } 3\end{array}$ \\
\hline Heavy clouds & $\begin{array}{l}\text { AM1.5, SMARTS defaults translated to } \\
\text { SBDART, with cloud optical depth of } 15\end{array}$ \\
\hline
\end{tabular}

the band gap energy, no electron-hole pair can be generated. However, for photons with energy that are higher than the band gap, electron-hole pairs will be generated, but the carriers with excess energy compared to the band gap will quickly lose their energy as heat and relax to the band edge. Therefore, the excess energy is lost. Band gap engineering of multijunction solar cells mainly focuses on reducing the energy loss by providing a well stratified way to selectively capture photons based on their energy levels. The energy loss in solar cell is mainly through two different mechanisms involving (i) photons with energies, $h v$, greater than the band gap energy, $E_{g}$, and (ii) photons with energies less than the band gap energy. The mechanisms are summarized in

$$
E\left(\text { loss }_{\text {total }}\right)=E\left(h v>E_{g}\right)+E\left(h v<E_{g}\right) .
$$

For a given band gap semiconductor material, and for photon energy larger than the band gap, the total loss in energy is

$$
E\left(h \nu>E_{g}\right)=\int_{0}^{\lambda_{g}} E_{\text {real }}(\lambda) \frac{h \nu-E_{g}}{h \nu} \mathrm{d} \lambda,
$$

where $\lambda_{g}$ is the wavelength corresponding to the band gap, $E_{\text {real }}(\lambda)$ is the integrated spectrum, $h v$ is the photon energy, and $E_{g}$ is the band gap of the material. For a given band gap semiconductor material with photon energy smaller than the band gap (i.e., photon not absorbed), the total loss in energy will be

$$
E\left(h \nu<E_{g}\right)=\int_{\lambda_{g}}^{i n f} E_{\text {real }}(\lambda) \mathrm{d} \lambda
$$

where inf denotes infinity. 


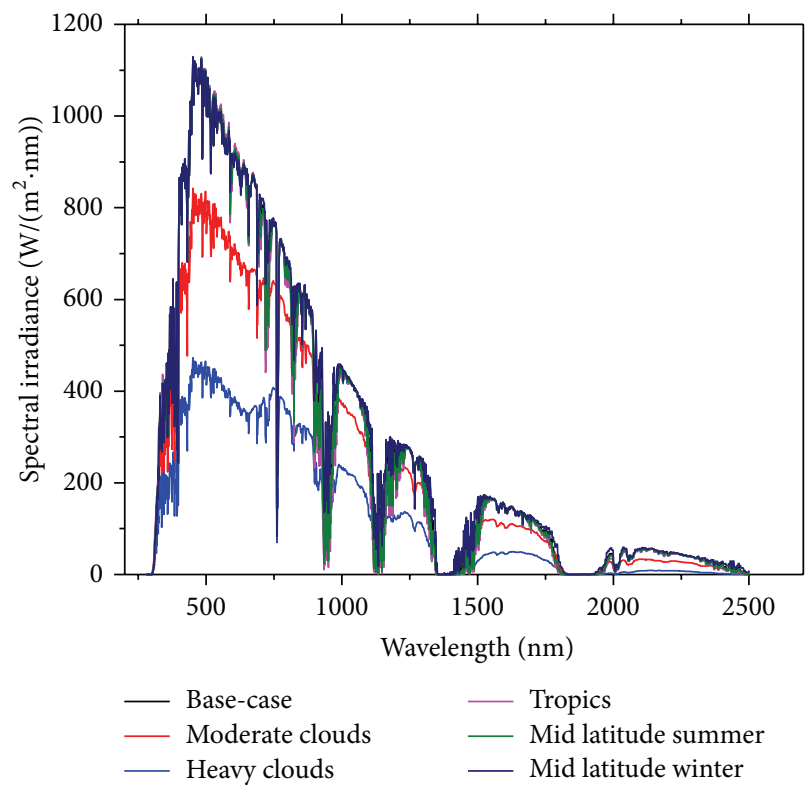

(a)

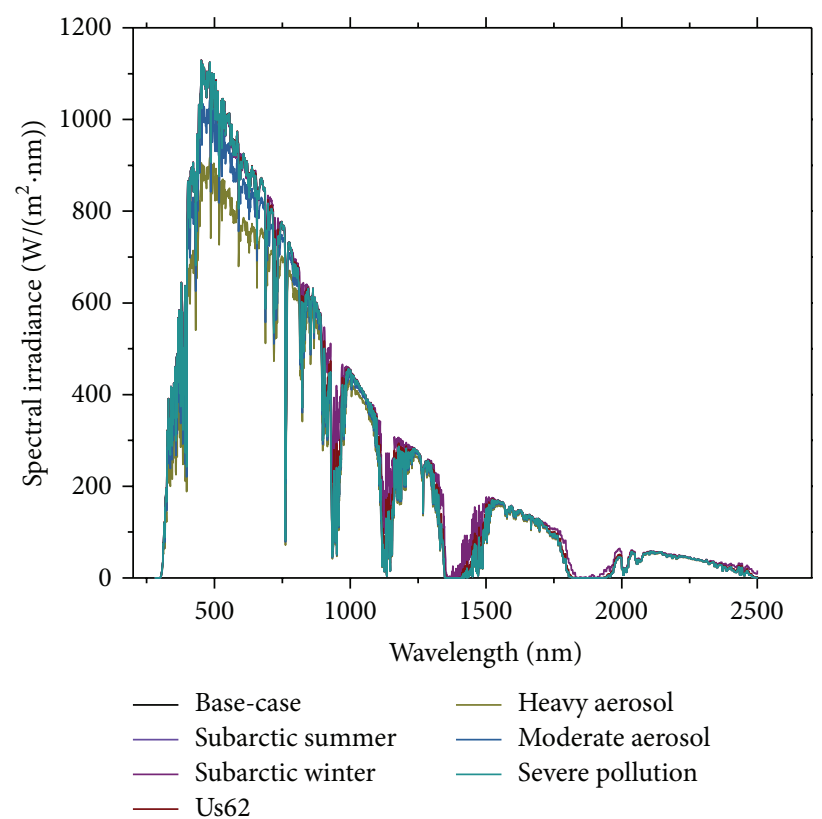

(b)

Figure 1: (a) and (b) Representative spectra for various air conditions.

For the case of a triple junction solar cell, the total energy loss would be

$$
\begin{aligned}
E\left(\text { loss }_{\text {total }}\right) & \\
= & E\left(\text { loss }_{1 \text { st-junction }}\right)+E\left(\text { loss }_{2 \text { nd-junction }}\right) \\
& \left.+E\left(\text { loss }_{3 \text { rd-junction }}\right)+E \text { (unabsorbed }\right) \\
= & \int_{310 \mathrm{~nm}}^{\lambda_{g, 1}} E_{\text {real }}(\lambda) \frac{h \nu-E_{g, 1}}{h \nu} \mathrm{d} \lambda \\
& +\int_{\lambda_{g, 1}}^{\lambda_{g, 2}} E_{\text {real }}(\lambda) \frac{h \nu-E_{g, 2}}{h \nu} \mathrm{d} \lambda \\
& +\int_{\lambda_{g, 2}}^{\lambda_{g, 3}} E_{\text {real }}(\lambda) \frac{h \nu-E_{g, 3}}{h \nu} \mathrm{d} \lambda \\
& +\int_{\lambda_{g, 3}}^{\text {inf }} E_{\text {real }}(\lambda) \mathrm{d} \lambda .
\end{aligned}
$$

Computer code based equation (4) was developed. The program allows the computer to find the band gap combinations through iterations that give the minimum radiation energy loss using the integrated spectrum. It is assumed all incoming photons are absorbed at junctions and no recombination occurs during the whole process. In the model, the lower band gap is pinned at $0.7 \mathrm{eV}$ since it is the InN bandgap and thus the minimum energy bandgap characteristic for $\mathrm{In}_{x} \mathrm{Ga}_{1-x} \mathrm{~N}$ alloys. It is also near the bottom of most other low-bandgap systems (e.g., Ge and GaSb).
TABLE 2: Optimized band gap(s) for a single bandgap and up to four bandgaps solar cells and the corresponding total radiation energy loss.

\begin{tabular}{lccccc}
\hline Number of cells & $E_{g, 1}(\mathrm{eV})$ & $E_{g, 2}$ & $E_{g, 3}$ & $E_{g, 4}$ & Total loss $\left(\mathrm{W} / \mathrm{m}^{2}\right)$ \\
\hline 1 & 1.13 & & & & 312 \\
2 & 1.74 & 0.94 & & & 209 \\
3 & 2.03 & 1.34 & 0.70 & & 153 \\
4 & 2.25 & 1.64 & 1.13 & 0.70 & 122 \\
\hline
\end{tabular}

Pinned at $0.7 \mathrm{eV}$ for smallest $E_{g}$.

\section{Results and Discussion}

3.1. Atmospheric Conditions Integrated Irradiant Spectrum. Figures 1(a) and 1(b) show the representative spectrum representing the atmospheric air conditions for various locations in comparison with the baseline case which was taken to be the spectrum for the AM1.5 on a clear day.

3.2. Band Gap Optimization. The AM1.5 global spectrum was used initially to establish the baseline case scenario for optimized band gaps under normal conditions. The actual bandgap optimization is performed by inputting weighted spectra for different air conditions. The air conditions used in the study varied from a clean summer day to a severe polluted case. Table 2 shows the optimized band gaps based upon total radiation energy loss using an AM1.5 G spectrum. Results of optimized band gaps with different air conditions are shown in Table 3.

The results clearly show a decline in total radiation energy loss as the number of junctions increases as more of the incoming radiation can be used in the cell. Although the 
TABLE 3: Optimized band gap(s) for (a) 1-junction, (b) 2-junctions, (c) 3-junctions, and (d) 4-junctions according to various air conditions.

\begin{tabular}{|c|c|c|c|c|c|c|c|c|c|c|c|c|}
\hline $\begin{array}{l}\text { Number } \\
\text { of } \\
\text { junctions }\end{array}$ & $\begin{array}{l}\text { Base } \\
\text { case }\end{array}$ & $\begin{array}{l}\text { Moderate } \\
\text { clouds }\end{array}$ & $\begin{array}{l}\text { Heavy } \\
\text { clouds }\end{array}$ & Tropics & $\begin{array}{l}\text { Mid latitude } \\
\text { summer }\end{array}$ & $\begin{array}{l}\text { Mid latitude } \\
\text { winter }\end{array}$ & $\begin{array}{l}\text { Subarctic } \\
\text { summer }\end{array}$ & $\begin{array}{c}\text { Subarctic } \\
\text { winter }\end{array}$ & Us62 & $\begin{array}{l}\text { Heavy } \\
\text { aerosol }\end{array}$ & $\begin{array}{l}\text { Moderate } \\
\text { aerosol }\end{array}$ & $\begin{array}{c}\text { Severe } \\
\text { pollution }\end{array}$ \\
\hline 1 & 1.13 & 1.13 & 1.13 & 1.13 & 1.13 & 1.12 & 1.13 & 1.12 & 1.12 & 1.13 & 1.13 & 1.13 \\
\hline \multirow{2}{*}{2} & 1.74 & 1.74 & 1.64 & 1.74 & 1.74 & 1.53 & 1.74 & 1.53 & 1.74 & 1.53 & 1.53 & 1.74 \\
\hline & 0.94 & 0.94 & 0.94 & 0.94 & 0.94 & 0.7 & 0.94 & 0.7 & 0.93 & 0.7 & 0.7 & 0.94 \\
\hline \multirow{3}{*}{3} & 2.03 & 2.03 & 2.12 & 2.12 & 2.12 & 2.04 & 2.03 & 2.04 & 2.04 & 2.02 & 2.03 & 2.03 \\
\hline & 1.34 & 1.34 & 1.4 & 1.39 & 1.38 & 1.34 & 1.34 & 1.34 & 1.34 & 1.34 & 1.34 & 1.34 \\
\hline & 0.7 & 0.7 & 0.93 & 0.7 & 0.7 & 0.7 & 0.7 & 0.7 & 0.7 & 0.7 & 0.7 & 0.7 \\
\hline \multirow{4}{*}{4} & 2.25 & 2.21 & 2.21 & 2.25 & 2.25 & 2.25 & 2.25 & 2.25 & 2.25 & 2.21 & 2.25 & 2.25 \\
\hline & 1.64 & 1.57 & 1.53 & 1.64 & 1.64 & 1.64 & 1.64 & 1.64 & 1.64 & 1.57 & 1.64 & 1.64 \\
\hline & 1.13 & 1.13 & 1.13 & 1.13 & 1.13 & 1.13 & 1.13 & 1.13 & 1.13 & 1.13 & 1.13 & 1.13 \\
\hline & 0.7 & 0.7 & 0.7 & 0.7 & 0.7 & 0.7 & 0.7 & 0.7 & 0.7 & 0.7 & 0.7 & 0.7 \\
\hline
\end{tabular}

last junction is pinned at $0.7 \mathrm{eV}$, a significant theoretical reduction in energy loss is achieved compared to the commercialized single junction solar cells currently fabricated with crystalline silicon with the approximately optimized bandgap. Compositions of the optimized $\operatorname{In}_{x} \mathrm{Ga}_{1-x} \mathrm{~N}$ alloy are usually determined using Vagard's law assuming the bowing parameter $b=1.43 \mathrm{eV}[26]$ :

$$
E_{g}(x)=x E_{g}(\mathrm{InN})+(1-x) E_{g}(\mathrm{GaN})-1.43 x(1-x) .
$$

The results indicate a change in the optimized band gap(s) for different air conditions, which can be attributed to the spectral change of radiation energy as seen in Figure 1. As can be seen in Figure 2, the simulations show only small variations in optimized band gap(s) for each case. This small shift is due to the relatively minor changes in relative irradiation energy along the wavelength axis though the irradiation energy for each case can change a lot at an arbitrary wavelength. It is important to note that the temporal variations (e.g., summer and winter) are also found to have an effect on the optimal band gap(s). Places with different pollution conditions may adopt difference cell design strategies for optimizing the cell performance. Long winter or summer areas can also benefit from this practical modeling. Heavily polluted areas have a spectral radiance which differs with a clear sky area and hence the solar panels for use in these two different regions/locales need to be custom designed to optimally absorb the majority of the photons in that particular locale.

Albedo contributions for snow have been shown to be quite significant for a single junction silicon solar cell [22] particularly for building-integrated PV systems [27]. However, results presented here show that for multijunction solar cells placed at less steep tilt angles the albedos have an insignificant contribution to the resultant spectrum incident on the solar module. This means that when designing solar systems for solar farms with small tilt angles and thus a smaller relative albedo contribution, it is more critical to take into account the spectral characteristics of the solar irradiance for that particular area rather than the specific albedo in the region. For example, going from the base condition to the subarctic condition changed the optimal energy of a tandem top cell by $13.7 \%$. For a tandem cell placed at subarctic region with $75 \%$ of the year in winter, the optimized band gap goes down to $1.53 \mathrm{eV}$ and $0.70 \mathrm{eV}$ instead of 1.73 and 0.94 for the first and second junction, respectively. The corresponding energy loss for this case is $228.03 \mathrm{~W} / \mathrm{m}^{2}$, which saves $2.4 \mathrm{~W} / \mathrm{m}^{2}$ compared to tandem cells designed without optimization. The loss in radiation energy can be accumulated when the local environment experiences more than one alteration condition listed above. When the model is used for optimization it can provide for more specific customization in more complicated local environments.

3.3. Future Work. In the current PV market, crystalline silicon is often less expensive than multijunction solar cells with rare exceptions such as thin film cells based on hydrogenated amorphous silicon materials. This study did not consider economics and only focuses on the initial design work to make multijunction solar cells meant for specific locations. As the development of multijunction cells is progressing rapidly it may be economically viable to optimize the design of PV for locations with abnormal spectra.

This study developed the optimal bandgaps for multijunction PV over a range of climate conditions, but further work is necessary to obtain optimal device geometries and optical enhancement strategies for this same selection of climate conditions. In this study it was assumed that the optical enhancement/light trapping was ideal so that the cells themselves could be optimized. A further refinement for future work could include a variable optical coupling with properties dependent on measured light trapping.

In addition, other materials systems capable of bandgap engineering with multijunction PV can be investigated using the same approach. Future work is needed to determine the material properties for materials of the bandgaps identified. In addition, more comprehensive rapid flux calculation methods using incomplete Riemann zeta functions as a replacement for the Bose-Einstein integral in detailed balance calculations for tandem cells can be used [28]. Once both electrical and optical properties are determined, the 

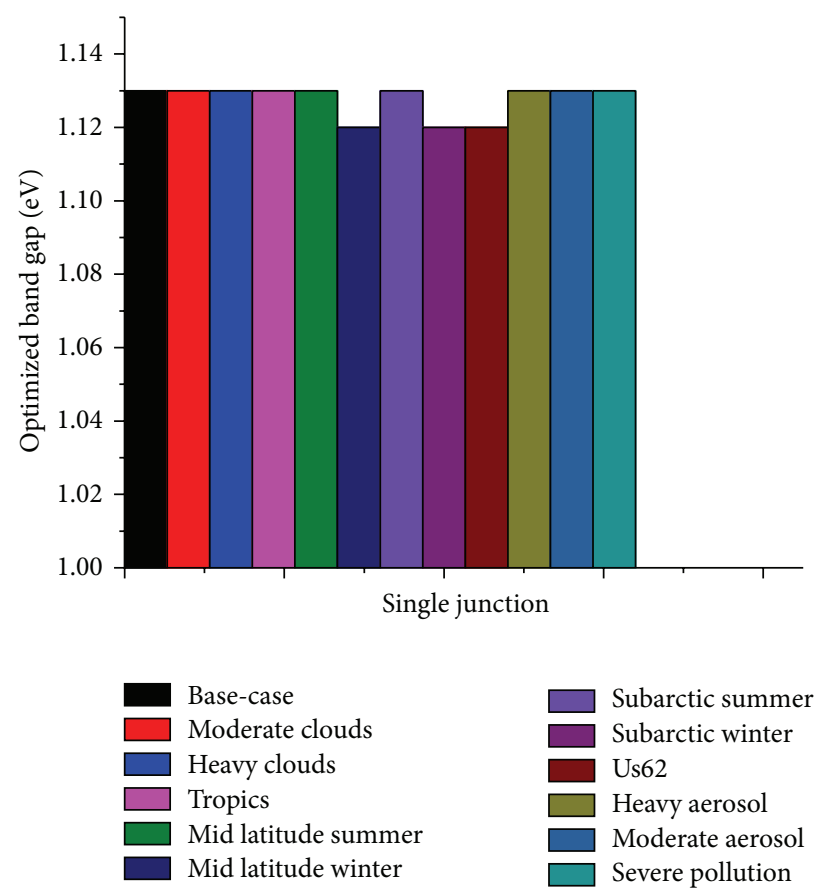

(a)

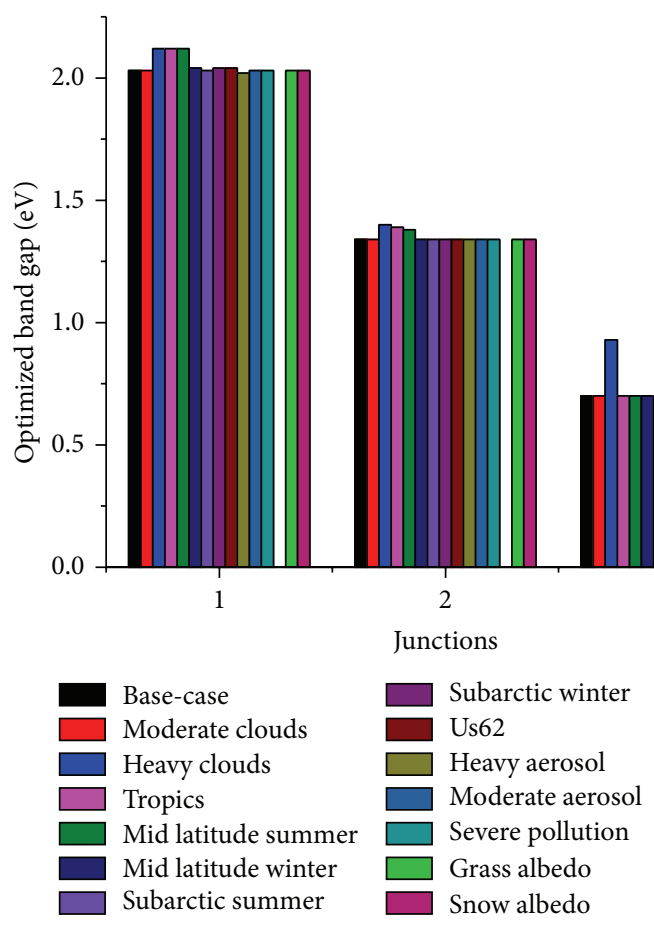

(c)

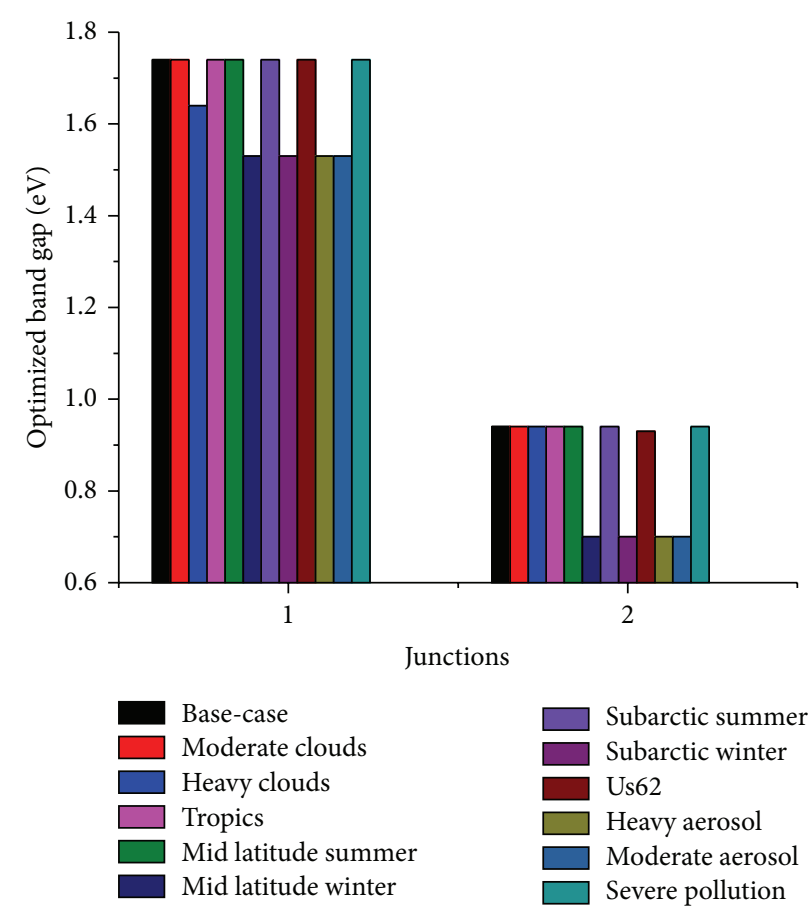

(b)

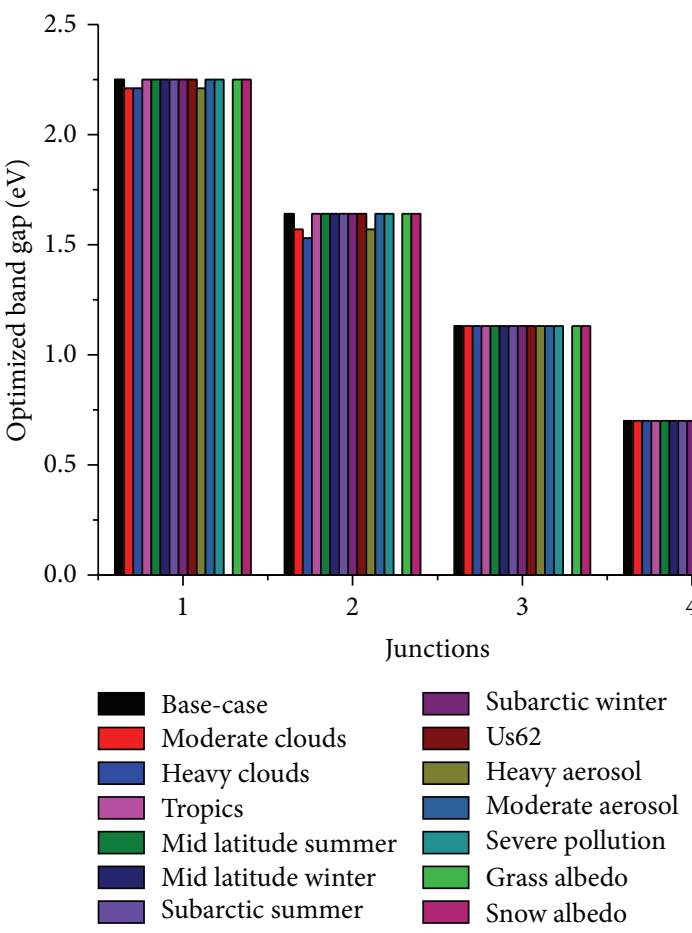

(d)

FIGURE 2: Optimized band gap(s) of PV for (a) 1-junction, (b) 2-junctions, (c) 3-junctions, and (d) 4-junctions for varying air conditions.

device properties such as energy band diagrams, quantum efficiency, and the $I-V$ characteristics of completed cells can be simulated with AMPS and other packages $[29,30]$. Then either AMPS $[31,32]$ or newer packages like wx-AMPS can be used to design and optimize the layers using simulations of the $I-V$ curves for tandem cells $[30,32]$. This should result in a monolithic, series-connected PV device with photocurrent matched junctions. Thus, these simulations can guide experiments toward the promise of high efficiency multijunction tandem cells. 
The $E_{g}$ of semiconductors tends to decrease as the temperature is increased. This is due to the interatomic spacing increasing with the amplitude of the atomic vibrations from increased thermal energy. Thus, the potential of the electrons in the material is decreased, which in turn reduces $E_{g}$. This study only considered standard testing conditions for temperature, so future work is necessary to model the effects of temperature and spectra on optimal bandgap engineering of PV for every location on the Earth using experimental meteorological data. In addition, although normally PV device performance degrades with temperature, there has been some recent work that showed an increase in electrical performance of specific types of PV if operated in solar photovoltaic thermal (PVT) systems with dispatch strategies that allowed for high temperature pulse annealing $[33,34]$. Thus, future work should consider this effect and the use of higher exergy PVT [35] for optimized multijunction bandgap engineering.

\section{Conclusions}

Band gap engineering for multijunction solar cells was carried out in order to improve the solar harvesting efficiency by minimizing incident radiation losses. Spectral irradiance characteristics due to prevailing atmospheric conditions were simulated to optimize the bandgaps of 1-, 2-, 3-, and 4junction devices. The effect of the air conditions on the spectral radiance is evident from the results and if ignored can result in suboptimal sizing of solar systems during the design stage.

\section{Conflict of Interests}

The authors declare that there is no conflict of interests regarding the publication of this paper.

\section{Acknowledgment}

The authors would like to acknowledge support from the Fulbright S \& T Fellowship.

\section{References}

[1] A. G. Bhuiyan, K. Sugita, A. Hashimoto, and A. Yamamoto, "InGaN solar cells: present state of the art and important challenges," IEEE Journal of Photovoltaics, vol. 2, no. 3, pp. 276293, 2012.

[2] D. V. P. McLaughlin and J. M. Pearce, "Progress in indium gallium nitride materials for solar photovoltaic energy conversion," Metallurgical and Materials Transactions A: Physical Metallurgy and Materials Science, vol. 44, no. 4, pp. 1947-1954, 2013.

[3] T. Takeuchi, H. Takeuchi, S. Sota, H. Sakai, H. Amano, and I. Akasaki, "Optical properties of strained AlGaN and GaInN on GaN," Japanese Journal of Applied Physics, vol. 36, no. 2, pp. L177-L179, 1997.

[4] X. Sun, W. B. Liu, D. S. Jiang et al., "Photoelectric characteristics of metal/InGaN/GaN heterojunction structure," Journal of Physics D: Applied Physics, vol. 41, no. 16, Article ID 165108, 2008.
[5] O. Jani, I. Ferguson, C. Honsberg, and S. Kurtz, "Design and characterization of GaN/InGaN solar cells," Applied Physics Letters, vol. 91, no. 13, Article ID 132117, 2007.

[6] X. Zhang, X. Wang, H. Xiao et al., "Simulation of $\operatorname{In}_{0.65} \mathrm{Ga}_{0.35} \mathrm{~N}$ single-junction solar cell," Journal of Physics D: Applied Physics, vol. 40, no. 23, pp. 7335-7338, 2007.

[7] E. A. Berkman, N. A. El-Masry, A. Emara, and S. M. Bedair, "Nearly lattice-matched $n$, $i$, and $p$ layers for InGaN $p-i-n$ photodiodes in the $365-500 \mathrm{~nm}$ spectral range," Applied Physics Letters, vol. 92, no. 10, Article ID 101118, 2008.

[8] L. Hsu and W. Walukiewicz, "Modeling of InGaN/Si tandem solar cells," Journal of Applied Physics, vol. 104, no. 2, Article ID 024507, 2008.

[9] O. Jani, B. Jampana, M. Mehta et al., "Optimization of GaN window layer for In GaN solar cells using polarization effect," in Proceedings of the 33rd IEEE Photovoltaic Specialists Conference (PVSC '08), pp. 1-4, IEEE, San Diego, Calif, USA, May 2008.

[10] X.-M. Cai, S.-W. Zeng, and B.-P. Zhang, "Fabrication and characterization of InGaN p-i-n homojunction solar cell," Applied Physics Letters, vol. 95, no. 17, Article ID 173504, 2009.

[11] R. Dahal, B. Pantha, J. Li, J. Y. Lin, and H. X. Jiang, "InGaN/GaN multiple quantum well solar cells with long operating wavelengths," Applied Physics Letters, vol. 94, no. 6, Article ID 063505, 2009.

[12] R. Horng, S. Lin, Y. Tsai et al., "Improved conversion efficiency of GaN/InGaN thin-film solar cells," IEEE Electron Device Letters, vol. 30, no. 7, pp. 724-726, 2009.

[13] D.-Y. Zhang, X.-H. Zheng, L.-J. Tang, J.-R. Dong, H. Wang, and $\mathrm{H}$. Yang, "Photovoltaic effects of InGaN/GaN double heterojunctions with $\mathrm{p}-\mathrm{GaN}$ nanorod arrays," IEEE Electron Device Letters, vol. 31, no. 12, pp. 1422-1424, 2010.

[14] E. Matioli, C. Neufeld, M. Iza et al., "High internal and external quantum efficiency InGaN/GaN solar cells," Applied Physics Letters, vol. 98, no. 2, Article ID 021102, 2011.

[15] S. Keating, M. G. Urquhart, D. V. P. McLaughlin, and J. M. Pearce, "Effects of substrate temperature on indium gallium nitride nanocolumn crystal growth," Crystal Growth \& Design, vol. 11, no. 2, pp. 565-568, 2011.

[16] M. Leszczynski, R. Czernecki, S. Krukowski et al., "Indium incorporation into InGaN and InAlN layers grown by metalorganic vapor phase epitaxy," Journal of Crystal Growth, vol. 318, no. 1, pp. 496-499, 2011.

[17] D. V. P. McLaughlin and J. M. Pearce, "Analytical model for the optical functions of indium gallium nitride with application to thin film solar photovoltaic cells," Materials Science and Engineering B, vol. 177, no. 2, pp. 239-244, 2012.

[18] J. M. Pearce, C. Zhang, J. Rozario, and J. Gwamuri, "The viability of nanotechnology-based InGaN solar photovoltaic devices for sustainable energy generation," MRS Online Proceedings Library, vol. 1558, 2013.

[19] A. Martí and G. L. Araújo, "Limiting efficiencies for photovoltaic energy conversion in multigap systems," Solar Energy Materials \& Solar Cells, vol. 43, no. 2, pp. 203-222, 1996.

[20] C. A. Gueymard, "Interdisciplinary applications of a versatile spectral solar irradiance model: a review," Energy, vol. 30, no. 9, pp. 1551-1576, 2005.

[21] C. A. Gueymard, "Prediction and validation of cloudless shortwave solar spectra incident on horizontal, tilted, or tracking surfaces," Solar Energy, vol. 82, no. 3, pp. 260-271, 2008.

[22] R. W. Andrews and J. M. Pearce, "The effect of spectral albedo on amorphous silicon and crystalline silicon solar photovoltaic device performance," Solar Energy, vol. 91, pp. 233-241, 2013. 
[23] https://github.com/zic3799/InGaN_Air/blob/master/InGaN Air.zip.

[24] "Simple Model of the Atmospheric Radiative Transfer of Sunshine, or SMARTS," http://www.nrel.gov/rredc/smarts/.

[25] P. Ricchiazzi, S. Yang, C. Gautier, and D. Sowle, "SBDART: a research and teaching software tool for plane-parallel radiative transfer in the earth's atmosphere," Bulletin of the American Meteorological Society, vol. 79, no. 10, pp. 2101-2114, 1998.

[26] J. Wu, W. Walukiewicz, K. M. Yu et al., "Unusual properties of the fundamental band gap of InN," Applied Physics Letters, vol. 80, no. 21, pp. 3967-3969, 2002.

[27] M. P. Brennan, A. L. Abramase, R. W. Andrews, and J. M. Pearce, "Effects of spectral albedo on solar photovoltaic devices," Solar Energy Materials \& Solar Cells, vol. 124, pp. 111-116, 2014.

[28] S. P. Bremner, M. Y. Levy, and C. B. Honsberg, "Analysis of tandem solar cell efficiencies under AM1.5G spectrum using a rapid flux calculation method," Progress in Photovoltaics: Research and Applications, vol. 16, no. 3, pp. 225-233, 2008.

[29] H. Zhu, A. K. Kalkan, J. Hou, and S. J. Fonash, "Applications of AMPS-1D for solar cell simulation," AIP Conference Proceedings, vol. 462, pp. 309-314, 1999.

[30] Y. Liu, Y. Sun, and A. Rockett, "Batch simulation of solar cells by using Matlab and wxAMPS," in Proceedings of the 38th IEEE Photovoltaic Specialists Conference (PVSC '12), pp. 902-905, June 2012.

[31] M. I. Kabir, Z. Ibrahim, K. Sopian, and N. Amin, "Effect of structural variations in amorphous silicon based single and multi-junction solar cells from numerical analysis," Solar Energy Materials \& Solar Cells, vol. 94, no. 9, pp. 1542-1545, 2010.

[32] wxAMPS, Engineering at Illinois. Solar Cells Simulation, FAQ, 2013, https://wiki.engr.illinois.edu/display/solarcellsim/FAQ.

[33] M. J. M. Pathak, J. M. Pearce, and S. J. Harrison, "Effects on amorphous silicon photovoltaic performance from hightemperature annealing pulses in photovoltaic thermal hybrid devices," Solar Energy Materials \& Solar Cells, vol. 100, pp. 199203, 2012.

[34] J. Rozario, A. H. Vora, S. K. Debnath, M. J. M. Pathak, and J. M. Pearce, "The effects of dispatch strategy on electrical performance of amorphous silicon-based solar photovoltaicthermal systems," Renewable Energy, vol. 68, pp. 459-465, 2014.

[35] M. J. M. Pathak, P. G. Sanders, and J. M. Pearce, "Optimizing limited solar roof access by exergy analysis of solar thermal, photovoltaic, and hybrid photovoltaic thermal systems," Applied Energy, vol. 120, pp. 115-124, 2014. 

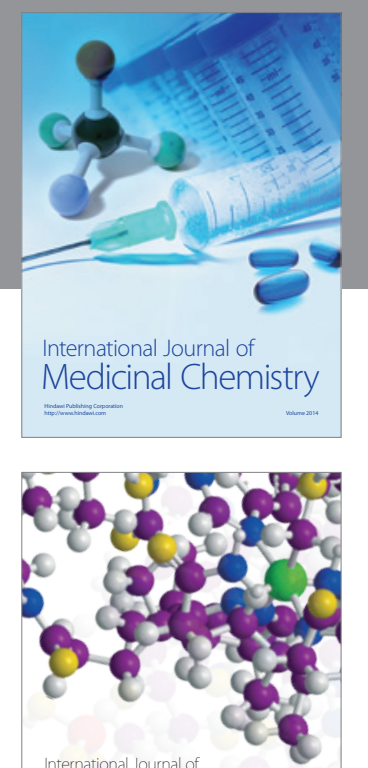

\section{Carbohydrate} Chemistry

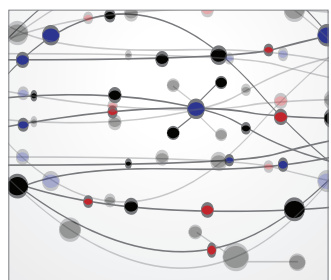

The Scientific World Journal
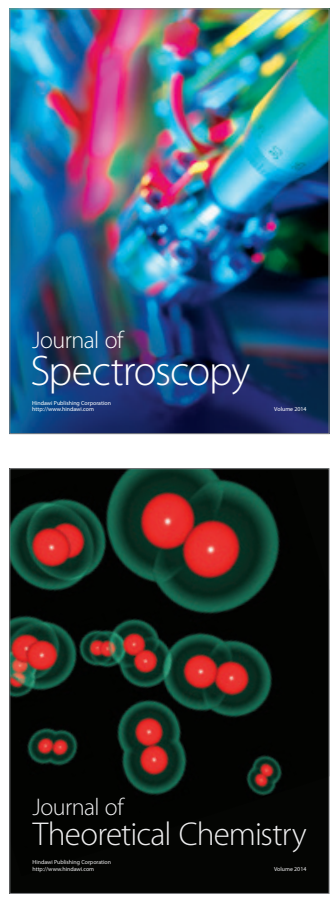
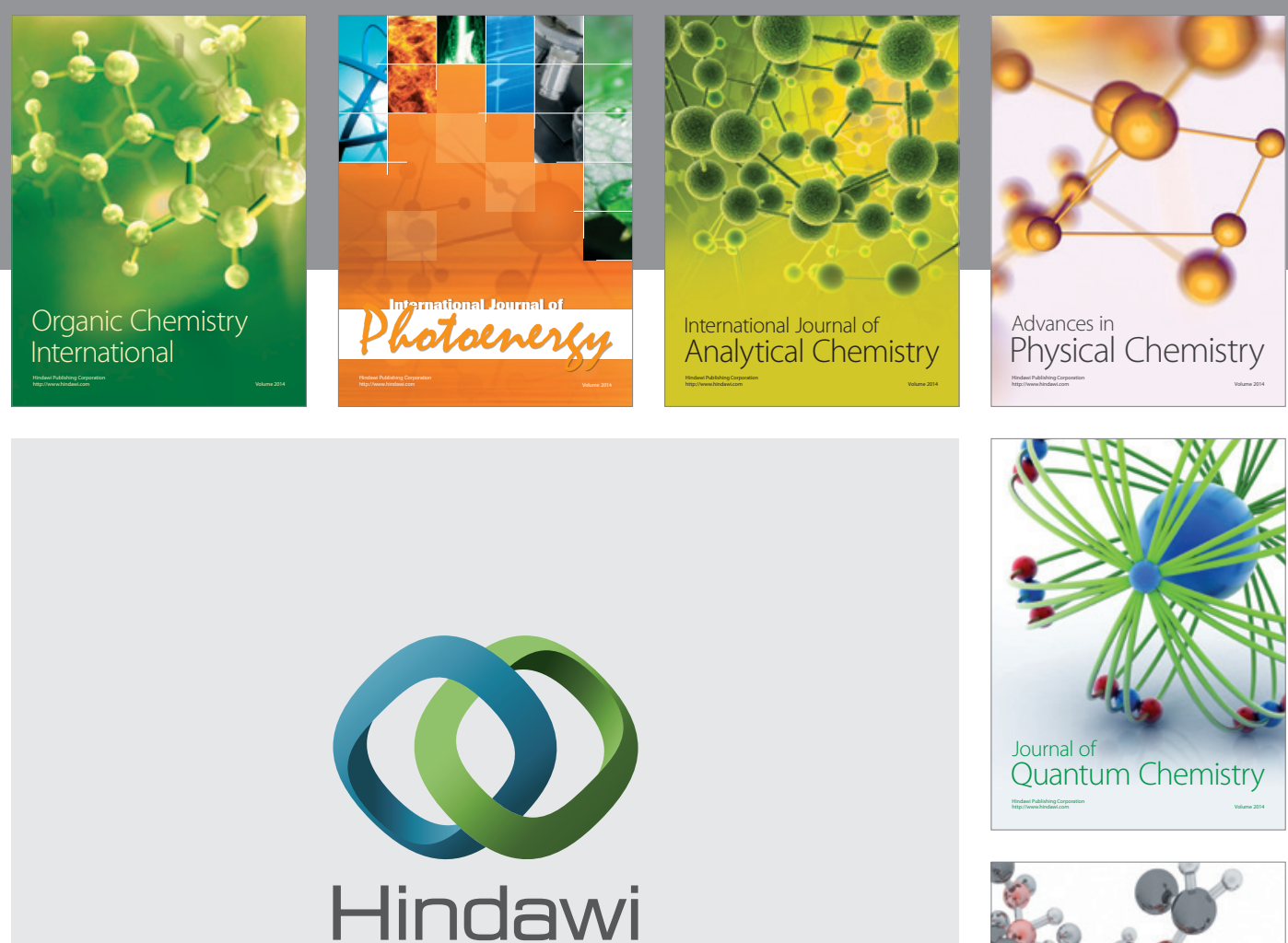

Submit your manuscripts at

http://www.hindawi.com

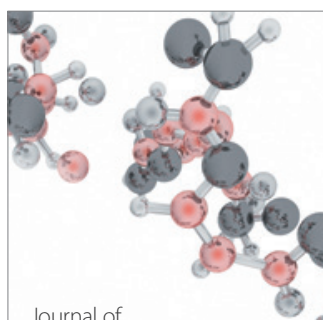

Analytical Methods

in Chemistry

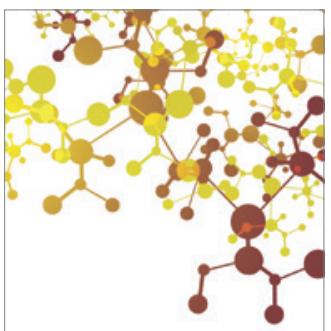

Journal of

Applied Chemistry

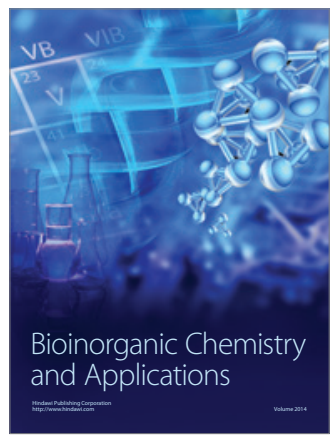

Inorganic Chemistry
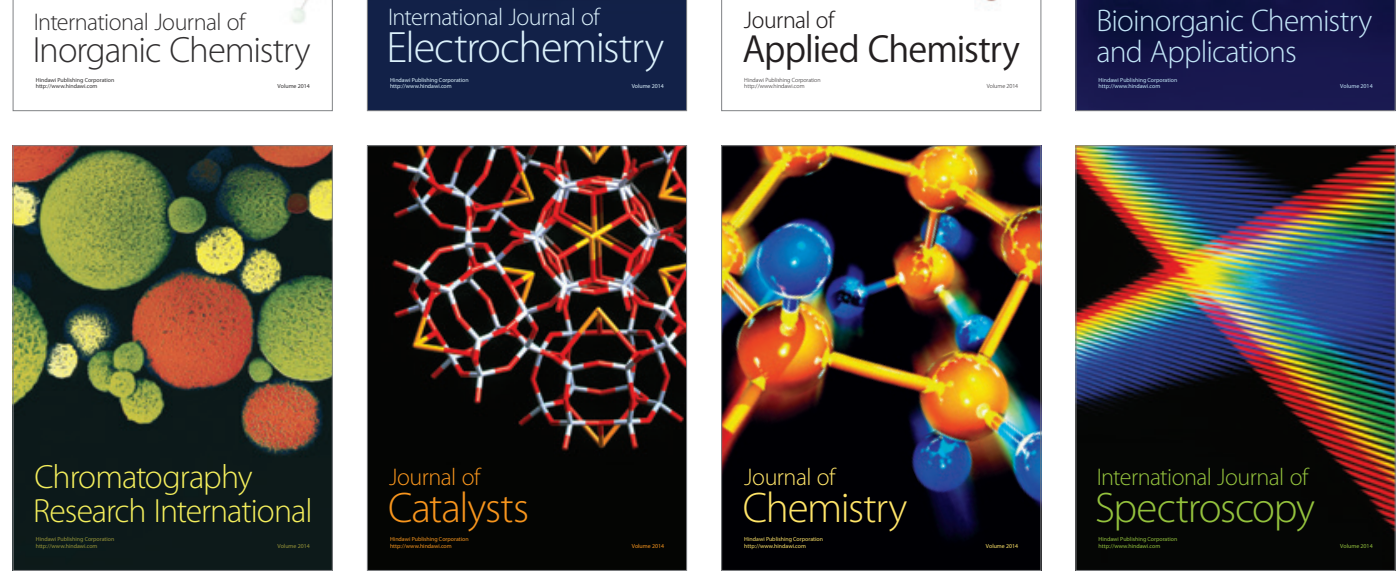